\title{
PREVALENCE OF RESTLESS LEGS SYNDROME IN PREGNANT WOMEN: A SYSTEMATIC REVIEW AND META-ANALYSIS
}

\author{
${ }^{1}$ School of Nursing and Midwifery, Student Research Committee, Kermanshah University of Medical Sciences, \\ Kermanshah, Iran \\ ${ }^{2}$ College of Nursing, University of Sulaimani, Sulaimani, Iraq \\ ${ }^{3}$ Department of Epidemiology and Biostatistics, School of Public Health, \\ Tehran University of Medical Sciences, Tehran, Iran \\ ${ }^{4}$ Spiritual Health Research Center, Research Institute for Health Development, Kurdistan University of Medical \\ Sciences, Sanandaj, Iran \\ ${ }^{5}$ Social Determinants of Health Research Center, School of Allied Medical Sciences, Shahrekord University of \\ Medical Sciences, Shahrekord, Iran \\ *Corresponding Authors
}

\section{ABSTRACT}

BACKGROUND. Restless legs syndrome (RLS) is a neurological disorder characterized by sleep disorders, which leads to adverse health consequences in the mother and fetus. Studies have reported different prevalence rates for RLS in pregnant women. This systematic review and meta-analysis aimed to estimate the prevalence of RLS in pregnant women.

METHODS. A literature search was performed via national and international databases, including Scientific Information Database (SID), MagIran, IranMedex, Google Scholar, Science Direct, PubMed, ProQuest, and Scopus. In total, 31 articles were selected without a time limit. The random effects model was used to analyze the data, and the heterogeneity between the studies was examined using the I 2 index. The analyses were performed in the Stata software, version 12 and $\mathrm{R}$, version 4.

RESULTS. The reviewed studies ( $\mathrm{n}=31$ ) were conducted on a total sample size of 59,151 , and the prevalence of RLS in pregnant women was estimated at 21.4\% [95\% confidence interval CI: 17.7-25.1]. Asia with a prevalence rate of $18.5 \%$, [95\% CI: 13.8-23.1] and Europe with a prevalence rate of $25.5 \%$, [95\% CI: 19.5-31.6] had the lowest and highest RLS prevalence, respectively. No significant correlations were observed between the prevalence of RLS, publication year of the articles $(\mathrm{P}=0.972)$, and participants' age $(\mathrm{P}=0.202)$.

CONCLUSION. According to the results, RLS is highly common in pregnant women, and it is essential to identify women with RLS to control and eliminate the adverse consequences of the disorder.

Keywords: prevalence, pregnancy, restless legs syndrome, $R L S$, systematic review

\section{INTRODUCTION}

Restless legs syndrome (RLS) is a neurological disorder that disrupts sleep and is characterized by four main symptoms, including unpleasant sensations in the legs, the deterioration of unpleasant sensations during periods of inactivity or while sitting, feeling of relief by moving the legs, and the onset or deterioration of unpleasant sensations in the legs during the night $(1,2)$. RLS patients describe these unpleasant sensations as similar to peristaltic movement on the skin, irritation, pain/stretching, feeling a flow of water on the legs, sensing insects in the bones, and sensing electricity in the legs. As the patients have to move or stretch their legs to reduce these feelings, the condition is referred to as RLS (3). It is important to differentiate RLS from other disorders that mimic the symptoms of this syndrome; such examples are neuroleptic-induced akathisia, cramps, and polyneuropathy (4). Although akathisia is associated with a sense of restlessness and the inability to sit still, it is not characterized by evident sleep disorders. Motor restlessness in akathisia is also generalized and internal (inner restlessness without sensory discomfort) and is not localized in

(C) National Institute of Public Health NIH - National Research Institute / Narodowy Instytut Zdrowia Publicznego PZH - Państwowy Instytut Badawczy 
a specific part of the body (5). Nocturnal leg cramps are caused by sudden, severe, and involuntary muscle contractions, which last for several minutes, and the residual discomfort and tenderness may persist for hours. This condition could be distinguished from restlessness by history. In polyneuropathy, symptoms of burning feet at night are possible, while the disorder is associated with no restlessness and no improvement with movement (4).

The prevalence of RLS in the general population is $5-15 \%$, and women are twice likely to experience RLS compared to men (6). Due to the hormonal changes during pregnancy, RLS might increase temporarily or permanently in pregnant women, and the prevalence of RLS has been reported to be 2-3 times higher in pregnant women compared to non-pregnant women $(6,7)$. Furthermore, a correlation has been observed between RLS and iron deficiency anemia. Iron is an important metal in the biological processes of the central nervous system, and its deficiency plays a key role in the pathophysiology of some neurodegenerative diseases, while it is also associated with the occurrence of RLS (8). Decreased iron and ferritin concentrations in the cerebrospinal fluid have also been reported in patients with RLS (9).

RLS treatment is particularly challenging in pregnant women due to the potential risk of the prescribed medication to the fetus (10). Studies have estimated the prevalence of RLS to be $2.9-43.7 \%$, and the discrepancies in this regard might be due to the differences in the sample populations, recall bias, and methodological limitations $(11,12)$. On the other hand, some researchers have attributed the discrepancy in the prevalence rate of RLS to racial and genetic differences $(13,14)$. The majority of the women experiencing RLS during pregnancy will most probably present with the symptoms after delivery (15). RLS is associated with depression, anxiety, sleep disorders, daytime fatigue, and cardiovascular diseases. In addition, RLS could lead to disturbances in performance and social isolation as it impairs the quality of life of the patients and interferes with their life satisfaction $(3,10,16)$. The results of a recent review indicated that RLS in pregnancy is associated with gestational hypertension, preeclampsia, and peripartum depression (17).

In RLS, periodic limb movements occur during sleep. Therefore, RLS during pregnancy leads to frequent awakenings and is associated with perinatal depression, gestational diabetes, preeclampsia, prolonged labor, C-section, and preterm birth (15, 18). Considering the higher sympathetic activities in women with RLS, the potential association between this syndrome and increased preeclampsia, and the correlation of RLS with higher mortality in the mother and child, accurate data are required on the overall prevalence of this syndrome. Extensive research has been focused on RLS in pregnant women, proposing different outcomes. For a better understanding of this condition, it is paramount to systematically review the previous studies in this regard and estimate the overall prevalence of RLS globally.

This systematic review and meta-analysis aimed to determine the prevalence of RLS in pregnant women.

\section{METHODS}

\section{Search Strategy}

A literature search was conducted via national and international databases without a time limit, including Scientific Information Database (SID), MagIran, IranMedex, Google Scholar, ScienceDirect, PubMed, ProQuest, and Scopus, using keywords such as (pregnancy OR pregnant OR gestation) AND (restless legs syndrome OR Ekbom syndrome OR RLS) AND (prevalence OR occurrence). The reference lists of the articles were also assessed for more relevant studies.

\section{Study Selection and Data Extraction}

Initially, the identified articles regarding the prevalence of RLS in pregnant women were collected, and more relevant articles were selected based on the inclusion and exclusion criteria. The inclusion criteria were: observational studies, reporting the prevalence of RLS in pregnant women, publications in Persian and English, and studies with moderate-to-high methodological quality. The exclusion criteria were the articles published in other languages than Persian and English, unavailable full text, repetitive studies, interventional studies, case reports, articles with low methodological quality, and studies with unclear ethical considerations.

In order to minimize bias, two researchers carried out the literature search independently. To reduce bias, the articles were studied blindly. For this purpose, the name of the journal and the names of the authors of the article were covered and articles without these details were reviewed by two researchers. Data extraction sheets were used to collect the data of the articles on the title, name of the first author, publication year, location of the study, sample size, diagnostic criteria (IRLSSG 1995/2003) $(6,19)$, data collection method (questionnaire/interview), study setting (hospital/clinic/community), pregnancy duration (third trimester/all months), and the number of the participants experiencing RLS. Based on the duration of pregnancy, the studies were divided into two groups of all months and the third pregnancy trimester. Notably, the studies performed on pregnant women in the first, second, and third trimesters of pregnancy were classified into the category of all months. The blinding method was used to reduce publication bias; 
the authors who extracted the data had no information about the articles and journals. The articles were examined based on the PRISMA checklist, which consisted of 29 items to assess the title, abstract, methodology, results, discussion, and funding sources of the selected studies (20).

To assess the methodological quality of the studies, we used 10 items of STROBE checklist, which were the title and abstract, objectives and hypotheses, research setting, inclusion criteria, sample size, statistical methods, descriptive data, interpretation of the findings, research limitations, and funding (21). Each article was scored one or zero in case of finding and not finding each item, respectively. Accordingly, the articles were divided into three categories of lowquality (scores 0-5), moderate (scores 6-8), and highquality (scores 9-10).

\section{Statistical Analysis}

Since the prevalence of RLS has a binomial distribution, the variance of prevalence was calculated using the binomial distribution variance formula, and the weighted mean was used to combine the prevalence rates of RLS in different studies. In order to evaluate heterogeneity between the selected studies, Cochran's Q test and I ${ }^{2}$ index were used. Heterogeneity was classified into three categories of $<25 \%$ (low heterogeneity), $25-75 \%$ (moderate heterogeneity), and $>75 \%$ (high heterogeneity). Based on the level of heterogeneity $(\mathrm{P}<0.0001), \mathrm{Q}=4,561.57$, and $\mathrm{I}^{2}=99.5 \%$, the DerSimonian and Laird random effects model was used to combine the studies and estimate the combined prevalence rate. Meta-regression analysis was used to determine the correlations between the prevalence of RLS, year of publication, and sample size. In addition, the ArcGIS 10 software (Stanford University, Stanford, CA, USA, 2010) was used to illustrate the distribution of RLS globally. Subgroup analysis was also carried out to assess the prevalence of RLS by continent, diagnostic criteria (IRLSSG 1995/2003), data collection method (interview/questionnaire), and study setting (hospital/community). Finally, in order to examine publication bias, the Egger's test and Funnel plot were employed. All the analyses were performed using the Stata software, version 12 and R, version 4.

\section{RESULTS}

All the published articles on RLS in pregnant women were reviewed systematically without a time limit. In the initial search, 63 articles were identified, and a total of 31 articles published during 2003-2017 were selected

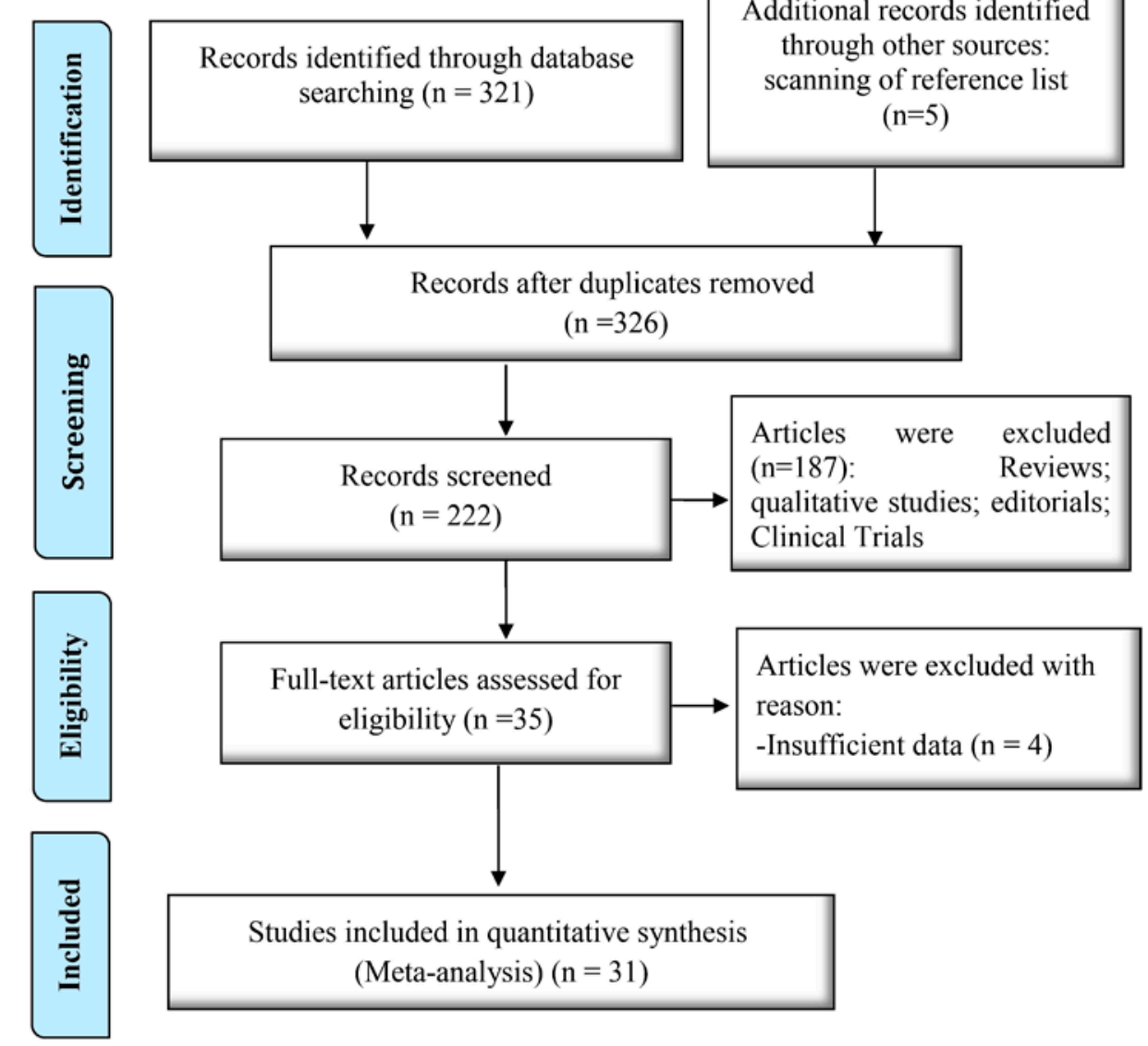

Figure 1. Flowchart of Screening and Selection of Qualified Articles. 
for the final analysis. Figure 1 depicts the screening and selection process and the number of articles.

\section{Summary of the Selected Studies}

The total sample size of the reviewed studies was 59,151 , with a mean of 1,908 subjects per study. The largest and smallest sample sizes belonged to the studies by Harano $(n=19,441)$ and Dehghan Nayeri $(n=110)$, respectively $(11,22)$. The highest and lowest prevalence rates of RLS were reported by Mebraban and Harano, respectively $(11,12)$. All the studies had a cross-sectional design, except the study by Mehraban (12), which was a cohort. In addition, all the studies had moderate and high methodological quality. Table I shows the data of the selected studies.

\section{Main Analysis}

According to the obtained results, the overall prevalence of RLS in pregnant women was $21.4 \%$ [95\% confidence interval CI: 17.7-25.1] (Figure 2).

Only six studies reported the prevalence of RLS during, before, and after pregnancy $(27,29,31,34$, $36,39)$. Accordingly, the prevalence of RLS during pregnancy was higher compared to before and after pregnancy (Figure 3).

The screening process indicated that the IRLSSG criteria 2003 had been used in 20 studies, and the IRLSSG criteria 1995 had been used in eight studies. In three other studies, other criteria (version 1995) had been used to diagnose RLS. Based on the IRLSSG criteria 2003 and 1995, the prevalence of RLS was $21.2 \%$ (95\% CI: $16.7-25.6)$ and $21 \%$ (95\% CI: $15.9-26)$,

Table I. Characteristics of the studies selected for final analysis

\begin{tabular}{|c|c|c|c|c|c|c|c|c|c|}
\hline First Author & Year & $\begin{array}{l}\text { Age of } \\
\text { Subjects } \\
\text { (year) }\end{array}$ & Country & $\begin{array}{c}\text { Sample } \\
\text { Size }\end{array}$ & $\begin{array}{c}\text { RLS } \\
\text { Prevalence } \\
(\%) \\
\end{array}$ & $\begin{array}{c}\text { IRLSSG } \\
\text { Criteria }\end{array}$ & $\begin{array}{c}\text { Data } \\
\text { Collection }\end{array}$ & Study Setting & $\begin{array}{c}\text { Pregnancy } \\
\text { Duration }\end{array}$ \\
\hline Suzuki (23) & 2003 & - & Japan & 16,528 & 19.9 & - & Self-report & Hospital & All Months \\
\hline Manconi (24) & 2004 & $31.8 \pm 4.7$ & Italy & 606 & 26.6 & 1995 & Interview & Hospital & All Months \\
\hline Tunc (25) & 2007 & - & Turkey & 146 & 26 & 2003 & Interview & Hospital & All Months \\
\hline Harano (11) & 2008 & $29.9 \pm 4.6$ & Japan & 19,441 & 2.9 & 2003 & Self-report & Hospital & All Months \\
\hline Sikandar (26) & 2009 & - & Pakistan & 279 & 30 & 2003 & Interview & Hospital & All Months \\
\hline $\begin{array}{l}\text { Ismailogullari } \\
(27)\end{array}$ & 2010 & - & Turkey & 983 & 10.4 & 1995 & Interview & Hospital & All Months \\
\hline Neau (28) & 2010 & $29.4 \pm 5$ & France & 186 & 32 & 2003 & Self-report & Hospital & All Months \\
\hline Neau (29) & 2010 & 30.1 & France & 1,022 & 24 & 2003 & Self-report & Community & All Months \\
\hline Alves (30) & 2010 & $27.3 \pm 5.9$ & Brazil & 524 & 13.5 & 2003 & Interview & Hospital & All Months \\
\hline Uglane (31) & 2011 & - & Norway & 251 & 34 & 1995 & Self-report & Hospital & All Months \\
\hline Balendran (32) & 2011 & - & Australia & 211 & 22.5 & 2003 & Self-report & Hospital & $3^{\text {rd }}$ Trimester \\
\hline Chen (33) & 2012 & - & Taiwan & 461 & 10.4 & 2003 & Interview & Hospital & All Months \\
\hline Sarberg (34) & 2012 & - & Sweden & 500 & 32 & 1995 & Self-report & oital & $3^{\text {rd }}$ Trimester \\
\hline $\begin{array}{l}\text { Dehghan } \\
\text { Nayeri (22) }\end{array}$ & 2012 & - & Iran & 110 & 22.7 & 2003 & Self-report & Hospital & All Months \\
\hline Kemlink (35) & 2013 & - & $\begin{array}{c}\text { Czech } \\
\text { Republic }\end{array}$ & 776 & 28 & 1995 & Self-report & Hospital & $3^{\text {rd }}$ Trimester \\
\hline Vahdat (36) & 2013 & $26.6 \pm 5.6$ & Iran & 443 & 17.8 & 2003 & Self-report & Hospital & All Months \\
\hline Neyal (37) & 2013 & - & Turkey & 241 & 39 & 2003 & Self-report & Unknown & All Months \\
\hline Minar (38) & 2013 & $30.8 \pm 4.6$ & Slovakia & 300 & 31.3 & 2003 & Self-report & Hospital & $3^{\text {rd }}$ Trimester \\
\hline Hubner (39) & 2013 & - & Switzerland & 501 & 12 & 2003 & Interview & Hospital & All Months \\
\hline Miri (40) & 2014 & $26.9 \pm 5.1$ & Iran & 443 & 17.8 & 2003 & Self-report & Hospital & All Months \\
\hline Wesstrom (41) & 2014 & $31.4 \pm 4.7$ & Switzerland & 1,428 & 12.3 & 1995 & Self-report & Hospital & $3^{\text {rd }}$ Trimester \\
\hline Cakmak (42) & 2014 & $27 \pm 5.9$ & Turkey & 500 & 15.4 & 1995 & Self-report & Hospital & All Months \\
\hline Terzi (7) & 2015 & - & Turkey & 600 & 13.8 & 2003 & Interview & Hospital & All Months \\
\hline Shang (43) & 2015 & $26 \pm 6.4$ & China & 1,584 & 11.2 & 2003 & Interview & Hospital & All Months \\
\hline Mehraban (12) & 2015 & - & Iran & 231 & 43.7 & 2003 & Self-report & Hospital & All Months \\
\hline $\mathrm{Ma} \mathrm{(44)}$ & 2015 & $25.8 \pm 5.4$ & China & 3,781 & 12 & 2003 & Interview & Hospital & All Months \\
\hline Lui (45) & 2016 & $26.7 \pm 5.4$ & China & 3,874 & 12.3 & 1995 & Interview & Hospital & All Months \\
\hline Innes (46) & 2016 & & USA & 498 & 24.5 & 2003 & Self-report & Community & All Months \\
\hline Oyieng’o (18) & 2016 & $29 \pm 6.1$ & USA & 1,000 & 35.5 & - & Self-report & Hospital & $3^{\text {rd }}$ Trimester \\
\hline Dunietz (47) & 2017 & - & USA & 1,563 & 36 & 2003 & Self-report & Hospital & $3^{\text {rd }}$ Trimester \\
\hline Hatanaka (48) & 2017 & - & Japan & 140 & 15.7 & - & Interview & Hospital & $3^{\text {rd }}$ Trimester \\
\hline
\end{tabular}

RLS - restless legs syndrome; IRLSSG - International Restless Legs Syndrome Study Group 


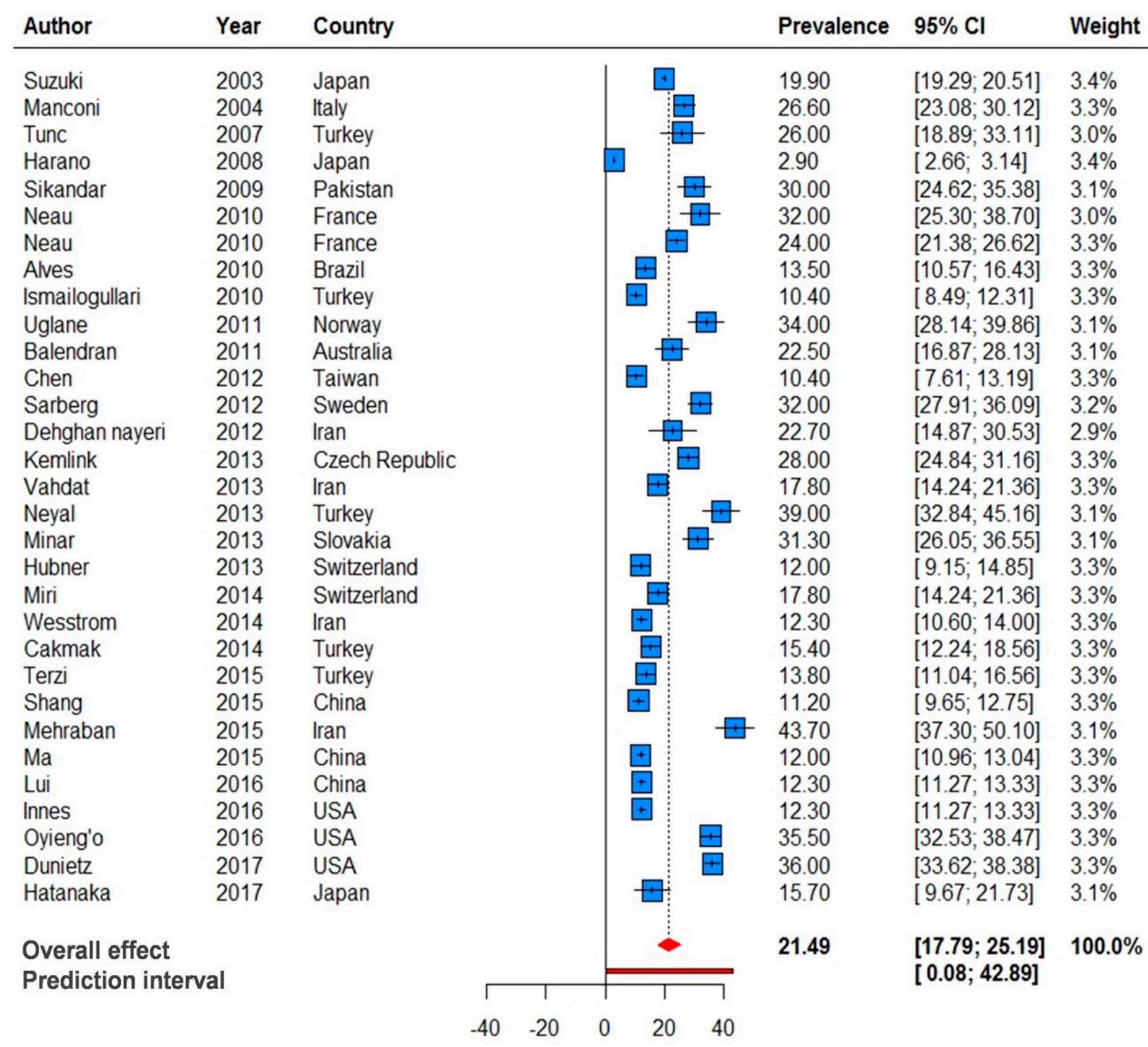

Figure 2. Forest plot of prevalence of restless legs syndrome (RLS) in pregnant women (95\% CI of each study shown as horizontal lines around central mean, midpoint of dotted line represents mean total score, lozenge shape shows CI of RLS prevalence)

respectively. In addition, the prevalence of RLS was estimated at $23.8 \%$ (95\% CI: $12.4-35.3)$ based on other criteria in three studies.

In terms of study setting, 28 studies were performed on hospitalized women, and two studies were performed on community-residing women. In the study by Neyal et al. (2013) (37), the place of sampling was not reported. In the mentioned studies, the prevalence of RLS was higher in the hospitalized women $(21 \%$; 95\% CI: 17.1-25.1) compared to the community-residing women (18\%; 95\% CI: 6.6-29.5). Among the selected studies, 13 used interviews, and 18 used self-report questionnaires to collect data on the symptoms of RLS. The prevalence of RLS was estimated at $25.8 \%$ (95\% CI: $19.5-32)$ in the studies using self-report questionnaires and 14.7\% (95\% CI: 12.8-16.5) in the studies using interviews (Table II).

In terms of continents, the lowest and highest prevalence rates of RLS were reported in the studies conducted in Asia (18.5\%; 95\% CI: 13.8-23.1) and Europe $(25.5 \%$; $95 \%$ CI: 19.5-31.6), respectively (Figure 4).

\section{Meta-regression}

In the current review, meta-regression was used to evaluate the correlations between the prevalence of RLS with the publication year of the studies, sample size, and mean age of the participants. No significant associations were reported between the prevalence of RLS, publication year of the studies, and mean age of the subjects. 


$\begin{array}{lll}\text { Author } & \text { Year } & \text { Country } \\ \text { Neau } & 2010 & \text { France } \\ \text { Ismailogulari } & \mathbf{2 0 1 0} & \text { Turkey } \\ \text { Vahdat } & \mathbf{2 0 1 3} & \text { ran }\end{array}$

A

\begin{tabular}{lll} 
Author & Year & Country \\
Neau & 2010 & France \\
Ismailogulari & 2010 & Turkey \\
Ugaane & 2011 & Norway \\
Vahdat & 2013 & tan \\
Hubner & 2013 & Switzerland \\
\hline
\end{tabular}

B

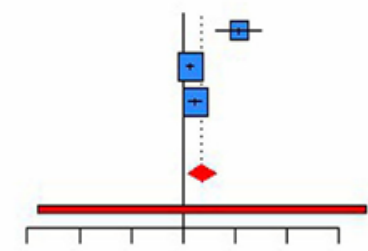

$\begin{array}{lllllll}-30 & -20 & -10 & 0 & 10 & 20 & 30\end{array}$

$\begin{array}{lll}\text { Prevalence } & \text { 95\% C } & \text { Weight } \\ & & \\ 10.75 & {[6.30 ; 15.20]} & 19.7 \% \\ 1.42 & {[0.68 ; 216]} & 41.7 \% \\ 226 & {[0.87 ; 3.64]} & 38.6 \% \\ 3.58 & {[0.90 ; 6.27]} & 100.0 \% \\ & {[-28.12 ; 3528]} & \end{array}$

$[-28.12 ; 3528]$

$\begin{array}{lll}\text { Prevalence } & \text { 95\% Cl } & \text { Weight } \\ 3226 & {[25.54 ; 38.98]} & 18.3 \% \\ 10.48 & {[8.56 ; 1239]} & 20.6 \% \\ 0.34 & {[-0.38 ; 1.06]} & 20.8 \% \\ 17.83 & {[14.27 ; 21.40]} & 20.0 \% \\ 11.58 & {[8.78 ; 14.38]} & 20.3 \% \\ 14.05 & {[5.78 ; \mathbf{2 2 3 3}]} & 100.0 \% \\ & {[-18.31 ; 46.42]} & \end{array}$

$\begin{array}{lllll}40 & -20 & 0 & 20 & 40\end{array}$

$\begin{array}{lll}\text { Prevalence } & 95 \% \mathrm{Cl} & \text { Weight } \\ & & \\ 11.29 & {[6.74 ; 15.84]} & 24.7 \% \\ 3.19 & {[1.01 ; 5.36]} & 36.0 \% \\ 240 & {[1.06 ; 3.73]} & 39.3 \% \\ 4.88 & {[1.33 ; 8.43]} & 100.0 \% \\ & {[-37.62 ; 47.38]} & \end{array}$

$\mathrm{C}$

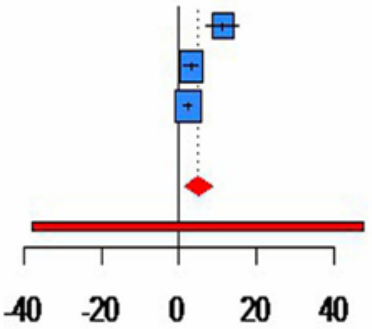

Figure 3. Forest plot of prevalence of RLS A) before, B) during, and C) after pregnancy (95\% CI of each study shown as horizontal lines around central mean, midpoint of dotted line represents mean total score, lozenge shape shows CI of RLS prevalence)

Table II. Prevalence of RLS in Studied Subgroups

\begin{tabular}{|c|c|c|c|c|c|c|c|c|}
\hline \multirow{2}{*}{\multicolumn{2}{|c|}{ Variable }} & \multirow{3}{*}{$\begin{array}{c}\text { No of } \\
\text { Studies }\end{array}$} & \multirow{3}{*}{$\begin{array}{c}\begin{array}{c}\text { Partici- } \\
\text { pants }\end{array} \\
32,565\end{array}$} & \multirow{3}{*}{$\begin{array}{c}\begin{array}{c}\text { Preva } \\
\text { lence }(\%)\end{array} \\
21.2\end{array}$} & \multirow{3}{*}{$\begin{array}{c}95 \% \mathrm{CI} \\
16.7-25.6\end{array}$} & \multicolumn{3}{|c|}{ Heterogeneity } \\
\hline & & & & & & \multirow{2}{*}{$\begin{array}{c}\begin{array}{l}\mathrm{I}^{2} \\
(\%)\end{array} \\
99.2\end{array}$} & \multirow{2}{*}{$\begin{array}{c}\mathrm{Q} \\
2,383.8\end{array}$} & \multirow{2}{*}{$\frac{\text { P-value }}{0.0001}$} \\
\hline \multirow{3}{*}{ Criteria } & IRLSSG 2003 & & & & & & & \\
\hline & IRLSSG 1995 & 8 & 8,918 & 21 & $15.9-26$ & 97.4 & 270.31 & 0.0001 \\
\hline & Other & 3 & 17,668 & 23.8 & $12.4-35.3$ & 98.1 & 104.4 & 0.0001 \\
\hline \multirow{4}{*}{ Continent } & Europe & 9 & 12,742 & 25.5 & $19.5-31.6$ & 96.7 & 241.08 & 0.0001 \\
\hline & Asia & 17 & 46,409 & 18.5 & $13.8-23.1$ & 99.5 & $3,534.96$ & 0.0001 \\
\hline & USA & 4 & 6,961 & 24.3 & $10.7-37.9$ & 99.4 & 477.97 & 0.0001 \\
\hline & Australia & 1 & 211 & 22.5 & $16.8-28.1$ & - & - & - \\
\hline \multirow{3}{*}{ Setting } & Hospital & 28 & 54,014 & 21.1 & $17.1-25.1$ & 99.5 & $5,163.2$ & 0.0001 \\
\hline & Community & 2 & 4,896 & 18 & $6.6-29.5$ & 98.5 & 66.35 & 0.0001 \\
\hline & Unknown & 1 & 241 & 39 & $32.8-45.1$ & - & - & - \\
\hline \multirow{2}{*}{$\begin{array}{c}\text { Pregnancy } \\
\text { Duration }\end{array}$} & 3rd Trimester & 8 & & 26.7 & $18.4-34.9$ & 98.1 & 372.22 & 0.0001 \\
\hline & All Months & 20 & & 19.6 & $15.6-23.5$ & 99.5 & $4,125.42$ & 0.0001 \\
\hline
\end{tabular}




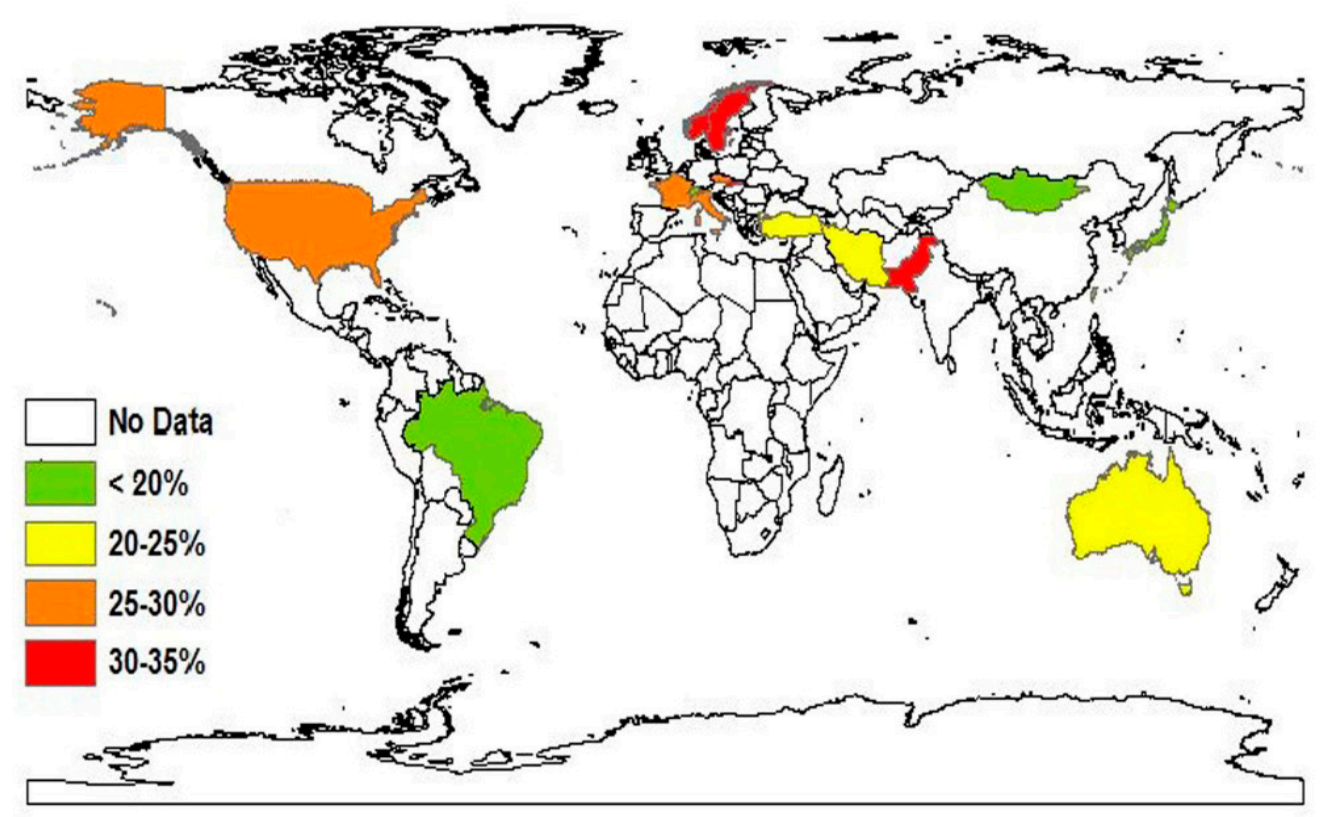

Figure 4. Prevalence of RLS in Pregnant Women in Different Geographical Regions (ArcGIS version 10).

Table III. Univariate Meta-regression of RLS Prevalence in Pregnant Women

\begin{tabular}{|c|c|c|c|c|}
\hline Variable & Coefficient & Standard Error & P-value & 95\% CI \\
\hline Year of Publication & -0.01 & 0.54 & 0.972 & $1.14-1.101$ \\
\hline Sample Size & 0.0008 & 0.0003 & 0.042 & $-0.0016-0.00003$ \\
\hline Mean Age & 1.73 & 1.28 & 0.202 & $-1.08-4.55$ \\
\hline
\end{tabular}

\section{DISCUSSION}

In the present study, we systematically reviewed a total of 31 studies conducted during 2003 November 2017 on a sample size of 59,151. In this meta-analysis, the random effects model was used to determine the prevalence of RLS in pregnant women, which was estimated at $21.4 \%$ (95\% CI: 17.7-25.1). Previous studies have shown that a large number of pregnant women experience RLS $(12,18,37)$. Varied prevalence rates of RLS have been reported in pregnant women in the previous studies in this regard based on various diagnostic criteria, different trimesters of pregnancy, racial background of the subjects, and different geographical locations (range: $2.9-43.7 \%)(11,12)$.

According to the current review, the prevalence of RLS is higher during pregnancy compared to before and after pregnancy, indicating that pregnancy may deteriorate RLS. Although the exact mechanism of RLS during pregnancy remains a matter of debate, several hypotheses have proposed predisposing factors such as hemoglobin level, iron deficiency, insufficient intake of iron supplements, hormonal and metabolic changes, caffeine consumption, nicotine use, and alcohol consumption (7). Furthermore, some researchers believe that the main hormones in pregnancy (estrogen, progesterone, prolactin, and thyroid hormones), which increase during pregnancy, play a pivotal role in the pathophysiology of RLS during this period (49). On the other hand, less than one-third of pregnant women experience the symptoms of RLS; therefore, hormonal changes cannot entirely explain the emergence of the syndrome (6).

The results of the present study indicated that the prevalence of RLS is higher in the third trimester of pregnancy compared to the other periods of pregnancy, which could be due to the increased need for iron in this period. Lesage believes that some RLS symptoms deteriorate in the third trimester of pregnancy, and some other symptoms are resolved after delivery (50). The rapid resolution of these unpleasant postpartum symptoms supports the hypothesis that RLS during pregnancy may occur due to hormonal changes (7). In this regard, a study indicated that pregnant women with RLS had higher levels of estradiol compared to pregnant women without RLS (51).

In addition to iron and folic acid deficiency and hormonal changes, Shang et al. (2015) considered the high prevalence of depression, anxiety, stress, insomnia, and fatigue during pregnancy to be the contributing factors to RLS (43). Despite the disagreements on the 
possible causes of RLS during pregnancy, researchers mainly agree on the challenges in the treatment of RLS during pregnancy. In other words, it is widely acknowledged that due to the potential dangers to the fetus, it is not possible to prescribe most of the medications that are normally effective in the alleviation of unpleasant RLS symptoms $(52,53)$.

In terms of the prevalence of RLS by continent, our findings indicated that the highest and lowest prevalence rates of RLS have been reported in Europe and Asia, respectively, which shows the impact of significant racial differences on the prevalence of RLS; however, the reason for the higher prevalence of this syndrome in the Caucasian population remains unclear (13). According to Lee (2009), the higher prevalence of RLS among European patients may due to racial differences (14), which stem from factors such as a genetic predisposition to RLS, dietary/medication regimens, and population lifestyle. RLS is a hereditary disease, and $63 \%$ of the patients have a first-degree relative with the same disorder. This highlights the key role of genetic factors and the autosomal dominant pattern observed in family history examinations (54).

With regard to epidemiological studies, Atkinson (2004) reported that the prevalence of RLS is 5-15\% in Europe and 1-3\% in Asia (55). Moreover, the subgroup analysis based on the type of screening indicated that the prevalence of RLS is $21.1 \%$ (95\% CI: $16.7-25.6)$ as shown by the IRLSSG criteria 2003 and $21 \%$ (95\% CI: 15.9-26) as shown by the IRLSSG criteria 1995. However, the prevalence of RLS is higher $(33.8 \%$; 95\% CI: 12.4-35.3) in the studies using other criteria (e.g., an urge to move the legs) compared to the studies using the IRLSSG criteria.

According to the results of the present study, the prevalence of RLS in pregnant women had been reported to be $11-19 \%$ before the introduction of a single diagnostic criterion and merely based on clinical observations (56). Following the introduction of the first diagnostic criterion for RLS based on the IRLSSG, the prevalence rate of the syndrome has been estimated at $20-27 \%$ in several studies $(23,24$, 57). After the revision of the diagnostic criteria, the prevalence of RLS is estimated at $2.9-39 \%$ in these studies $(11,25,37)$.

Our findings indicated that the prevalence of RLS is higher in the studies using self-report questionnaires (25.8\%; 95\% CI: 19.5-32) compared to those using interviews (14.7\%; 95\% CI: 12.8-16.5). Interview results appear to be more accurate than questionnaires since questionnaires may overestimate the prevalence rate as the respondents may not fully understand the questions, and the mimics that cause similar symptoms cannot be excluded.
In the current review, the prevalence of RLS was observed to be higher in hospitalized pregnant women compared to community-residing pregnant women. The difference in this regard could be attributed to the intensity of the pregnancy-related discomfort felt by pregnant women, which may lead to their hospitalization. Numerous studies have emphasized that age is a significant risk factor for the development of RLS $(29,36,38)$. However, the meta-regression analyses indicated no significant association between the mean age of subjects and the prevalence of RLS. Previous findings are contradictory regarding the association between age and the prevalence of RLS. In American and European societies, the prevalence of this syndrome has been reported to be higher with increased age, while no such correlation has been observed in Asian countries (58). Similar to the present study, the research conducted by Chen et al. (2018) had limitations in terms of the literature search strategy (59).

\section{CONCLUSION}

RLS is highly common in pregnant women, and one per five pregnant women experiences this syndrome. Given the adverse health consequences of RLS in the mother and fetus, the rapid identification of RLS patients seems essential.

\section{Abbreviations \\ CI: Confidence interval \\ IRLSSG: International Restless Legs Syndrome Study Group \\ RLS: Restless Leg Syndrome \\ SID: Scientific Information Database}

Ethical approval and consent to participate: Not applicable.

Conflicts of interest: None declared.

Funding: This study was financially supported by Kermanshah University of Medical Sciences, Iran.

\section{Acknowledgements}

Hereby, we extend our gratitude to the Research Deputy of Kermanshah University of Medical Sciences for the acceptance, approval, and financial support of this research project.

\section{REFERENCES}

1. Hensley JG. Leg cramps and restless legs syndrome during pregnancy. J Midwifery Womens Health. 2009;54(3):211-8. doi: 10.1016/j.jmwh.2009.01.003

2. Yang X, Liu B, Yang B, et al. Prevalence of restless legs syndrome in individuals with migraine: a systematic review and meta-analysis of 
observational studies. Neurol Sci. 2018;39(11):192734. doi: 10.1007/s10072-018-3527-7

3. Habibzade H, Khalkhali H, Ghaneii R. Study of the relationship between restless legs syndrome and sleep disturbance among patients in Critical Care Units. IJCCN. 2011;4(3):153-8.

4. Cotter PE, T O'Keeffe S. Restless leg syndrome: is it a real problem? Ther Clin Risk Manag. 2006;2(4):465. doi: 10.2147/tcrm.2006.2.4.465

5. Benes H, Walters AS, Allen RP, et al. Definition of restless legs syndrome, how to diagnose it, and how to differentiate it from RLS mimics. Mov Disord. 2007;22(S18):S401-S8. doi: 10.1002/mds.21604

6. Walters AS, Aldrich MS, Allen R, et al. Toward a better definition of the restless legs syndrome. Mov Disord. 1995;10(5):634-42. DOI: 610.1002/ mds. 870100517.

7. Terzi H, Terzi R, Zeybek B, et al. Restless legs syndrome is related to obstructive sleep apnea symptoms during pregnancy. Sleep Breath. 2015;19(1):73-8. doi:10.1007/s11325-014-0964-2.

8. Telarović S, Čondić L. Frequency of iron deficiency anemia in pregnant and non-pregnant women suffering from restless legs syndrome. Hematology. 2019;24(1):263-7. doi:10.1080/160784 54.2018 .1560935

9. Godau J, Klose U, Di Santo A, et al. Multiregional brain iron deficiency in restless legs syndrome. Mov Disord. 2008;23(8):1184-7. doi:10.1002/ mds. 22070

10. Ghanei Gheshlagh R, Lanjavani T, Lazari N, Moslemi B. Comparison of the quality of life in pregnant women with and without restless legs syndrome. J Clin Nurs Midwifery. 2014;3(1):54-61.

11. Harano S, Ohida T, Kaneita Y, et al. Prevalence of restless legs syndrome with pregnancy and the relationship with sleep disorders in the Japanese large population. Sleep Biol Rhythms. 2008;6(2):102-9. DOI: 10.1111/j.4798425.2008.00343.x.

12. Meharaban Z, Yahya S, Sadegniiat K. Restless Legs Syndrome During Pregnancy and Preterm Birth in Women Referred to Health Centers of Ardabil. Iran Red Crescent Med J. 2015;17(12):1-6. doi: $10.5812 /$ ircmj.24438.

13. Ondo WG. Restless Legs Syndrome. Curr Neurol Neurosci Rep. 2005;5:266-74. doi: 10.1007/s11910005-0071-7.

14. Lee J. A review of restless legs syndrome in patients on hemodialysis. Kidney. 2009;18(1):9-13. doi: 0.1007/s00596-008-0055-0.

15. Prosperetti C, Manconi M. Restless Legs Syndrome/Willis-Ekbom Disease and Pregnancy. Sleep Med Clin. 2015;10(3):323-9. doi: 10.1016/j. jsmc.2015.05.016.
16. Ghanei R, Hemati-Maslak-Pak M, Ghosi S, et al. Restless legs syndrome and the quality of sleep in type II diabetes. Feyz. 2011;15(3).

17. Steinweg K, Nippita T, Cistulli PA, Bin YS. Maternal and neonatal outcomes associated with restless legs syndrome in pregnancy: A systematic review. Sleep Med Rev. 2020:101359. doi: 10.1016/j. smrv.2020.101359

18. Oyieng'o DO, Kirwa K, Tong I, et al. Restless legs symptoms and pregnancy and neonatal outcomes. Clin Ther. 2016;38(2):256-64. doi: 10.1016/j. clinthera.2015.11.021.

19. Allen RP, Picchietti D, Hening WA, et al. Restless Legs Syndrome Diagnosis and Epidemiology workshop at the National Institutes of Health; International Restless Legs Syndrome Study Group. Restless legs syndrome: diagnostic criteria, special considerations, and epidemiology. A report from the restless legs syndrome diagnosis and epidemiology workshop at the National Institutes of Health. Sleep Med. 2003;4(2):101-19. doi: 10.1016/S1389-9457(03)00010-8

20. Moher D, Liberati A, Tetzlaff J, et al. Preferred reporting items for systematic reviews and metaanalyses: the PRISMA statement. PLoS med. 2009;6(7):e1000097. doi:10.1371/journal.pmed.

21. Farrugia M, Kirsch A. Application of the Strengthening the Reporting of Observational Studies in Epidemiology (STROBE) statement to publications on endoscopic treatment for vesicoureteral reflux. J Pediatr Urol. 2017;13(3):320 5. doi: 10.1016/j.jpurol.2017.02.005

22. Dehghan Nayeri N GR, Rezaee K. The relationship between Restless legs syndrome and sleep quality disorder in pregnant women. IJOGI. 2012;15(15):17.

23. Suzuki K, Ohida T, Sone T, et al. The prevalence of restless legs syndrome among pregnant women in Japan and the relationship between restless legs syndrome and sleep problems. Sleep. 2003;26(6):673-7. doi: 10.1093/sleep/26.6.673

24. Manconi M, Govoni V, De Vito A, et al. Pregnancy as a risk factor for restless legs syndrome. Sleep Med. 2004;5(3):305-8. doi: 10.1016/j. sleep.2004.01.013.

25. Tunç T, Karadağ YS, Doğulu F, et al. Predisposing factors of restless legs syndrome in pregnancy. Mov Disord. 2007;22(5):627-31. doi: 10.1002/ mds.21291.

26. Sikandar R, Khealani BA, Wasay M. Predictors of restless legs syndrome in pregnancy: a hospital based cross sectional survey from Pakistan. Sleep Med. 2009;10(6):676-8. doi: 10.1016/j. sleep.2008.06.011.

27. Ismailogullari S, Ozturk A, Mazicioglu MM, et al. Restless legs syndrome and pregnancy in Kayseri, Turkey: a hospital based survey. Sleep 
Biol Rhythms. 2010;8(2):137-43. doi: 10.1111/j.4798425.2010.00437.x.

28. Neau JP, Marion P, Mathis S, et al. Restless legs syndrome and pregnancy: follow-up of pregnant women before and after delivery. Eur Neurol. 2010;64(6):361-6. doi: 10.1159/000322124.

29. Neau J-P, Porcheron A, Mathis S, et al. Restless legs syndrome and pregnancy: a questionnaire study in the Poitiers District, France. European neurology. 2010;64(5):268-74. doi: 10.1159/000321413.

30. Alves DAG, de Carvalho LBC, de Morais JF, et al. Restless legs syndrome during pregnancy in Brazilian women. Sleep Med. 2010;11(10):1049-54. doi: 10.16/j.sleep.2010.06.006.

31. Uglane MT, Westad S, Backe B. Restless legs syndrome in pregnancy is a frequent disorder with a good prognosis. Acta Obstet Gynecol Scand. 2011; 90(9):1046-1048. doi: 10.111/j.6000412.2011.01157.x.

32. Balendran J, Champion D, Jaaniste $\mathrm{T}$, et al. A common sleep disorder in pregnancy: restless legs syndrome and its predictors. Aust N Z J Obstet Gynaecol. 2011; 51 (3): 262-64. doi: 10.1111/j.479828x.2011.01294.x.

33. Chen P-H, Liou K-C, Chen C-P, et al. Risk factors and prevalence rate of restless legs syndrome among pregnant women in Taiwan. Sleep Med. 2012;13(9):1153-7. doi: 10.016/j.sleep.2012.06.008.

34. Sarberg M, Josefsson A, Wiréhn AB, et al. Restless legs syndrome during and after pregnancy and its relation to snoring. Acta Obstet Gynecol Scand. 2012;91(7):850-5.

35. Kemlink D, Plchova L, Srutkova Z, et al. Restless legs syndrome during pregnancy in czech women. Sleep Med. 2013;14:e167. doi: 10.1016/j. sleep.2013.11.388.

36. Vahdat M, Sariri E, Miri S, et al. Prevalence and associated features of restless legs syndrome in a population of Iranian women during pregnancy. Int J Gynaecol Obstet. 2013;123(1):46-9. doi: 10.1016/j.ijgo.2013.04.023.

37. Neyal A, Aslan R, Benbir G, et al. Prevalence of restless legs syndrome in pregnancy and associated conditions in a Turkish population. J Neurol Sci. 2013;333:e655. doi: 10.1016/j.jns.2013.07.270.

38. Minár M, Habánová H, Rusňák I, et al. Prevalence and impact of restless legs syndrome in pregnancy. Neuro Endocrinol Lett. 2013;34(5):366-71.

39. Hübner A, Krafft A, Gadient S, et al. Characteristics and determinants of restless legs syndrome in pregnancy A prospective study. Neurology. 2013;80 (8): 738-42. DOI: 10.1212/ WNL.0b013e318283baf3

40. Miri S, Rohani M, Vahdat M, et al. Presenting features of idiopathic versus secondary restless legs syndrome in pregnancy. Iran $\mathrm{J}$ Neurol. 2014;13(4):241.
41. Wesström J, Skalkidou A, Manconi M, et al. Prepregnancy restless legs syndrome (Willis-Ekbom Disease) is associated with perinatal depression. J Clin Sleep Med. 2014;10(5):527. doi: 10.5664/ jcsm.3704

42. Çakmak B, Metin ZF, Karatas A, et al. Restless leg syndrome in pregnancy. Perinat J. 2014;22(1):1-5. doi:10.2399/prn.14.0221001.

43. Shang X, Yang J, Guo Yet al. Restless legs syndrome among pregnant women in China: prevalence and risk factors. Sleep Breath. 2015;19(3):1093-9. doi: 10.07/s11325-014-1089-3.

44. Ma S, Shang X, Guo Y, et al. Restless legs syndrome and hypertension in Chinese pregnant women. Neurol Sci. 2015;36(6):877-81. doi: 10.1007/s10072-015-2094-4

45. Liu G, Li L, Zhang J, et al. Restless legs syndrome and pregnancy or delivery complications in China: a representative survey. Sleep Med. 2016;17:15862. doi: 10.1016/j.sleep.2015.02.541.

46. Innes KE, Kandati S, Flack KL, et al. The relationship of restless legs syndrome to history of pregnancy-induced hypertension. J Womens Health (Larchmt). 2016;25(4):397-408. doi: 10.1089/jwh.2015.5484

47. Dunietz GL, Lisabeth LD, Shedden K, et al. Restless legs syndrome and sleep-wake disturbances in pregnancy. J Clin Sleep Med. 2017;13(7):863. doi: https://doi.org/10.5664/jcsm.6654

48. Hatanaka A, Eto H, Kato C, et al. Prevalence and clinical features of restless legs syndrome among Japanese pregnant women without gestational complications. Sleep Biol Rhythms. 2017;15(2):1836. doi: https://doi.org/10.1007/s41105-016-0086-2

49. Srivanitchapoom P, Pandey S, Hallett M. Restless legs syndrome and pregnancy: a review. Parkinsonism Relat Disord. 2014;20(7):716-22. doi: 10.1016/j.parkreldis.2014.03.027.

50. Lesage S, Earley CJ. Restless legs syndrome. Curr Treat Options Neurol. 2004;6(3):209-19. doi: 10.1007/s11940-004-0013-8

51. Fulda S, Stalla G, Wetter T. Prevalence of the restless legs syndrome in transsexual patients: the hormonal hypothesis revisited. J Neurol. 2007;254(12):1748. doi: 10.1007/s00415-007-06246

52. DeSimone EM, Petrov K. Restless legs syndrome: a common, underdiagnosed disorder. US Pharm. 2009;3 (1): 24-29. doi: 10.1016/B978-0750675185.10007-2

53. Bartel $1 \mathrm{~S}$, Zallek S. Intravenous magnesium sulfate may relieve restless legs syndrome in pregnancy. J Clin Sleep Med. 2006;2(02):187-8. doi: $10.5664 /$ jcsm. 26515

54. Didato G, Di Giacomo R, Rosa GJ, et al. Restless legs syndrome across the lifespan: Symptoms, pathophysiology, management and daily life impact 
of the different patterns of disease presentation. Int J Environ Res Public Health. 2020;17(10):3658. doi: 10.3390/ijerph17103658

55. Atkinson M, Allen R, DuChane J, et al. Validation of the Restless Legs Syndrome Quality of Life Instrument (RLS-QLI): findings of a consortium of national experts and the RLS Foundation. Qual Life Res. 2004;13(3):679-93. doi: 10.1023/B:QURE.0000021322.22011.d0.

56. Yeh P, Walters AS, Tsuang JW. Restless legs syndrome: a comprehensive overview on its epidemiology, risk factors, and treatment. Sleep Breath. 2012;16(4):987-1007. doi: 10./s11325-0110606-x.

57. Lee KA, Zaffke ME, Baratte-Beebe K. Restless legs syndrome and sleep disturbance during pregnancy: the role of folate and iron. J Womens Health Gend Based Med. 2001;10(4):335-41. doi:10.1089/152460901750269652. .

58. Ohayon MM, O'Hara R, Vitiello MV. Epidemiology of restless legs syndrome: a synthesis of the literature. Sleep Med Rev. 2012;16(4):283-95. doi: 10.1016/j.smrv.2011.05.002.
59. Chen S-J, Shi L, Bao Y-P, et al. Prevalence of restless legs syndrome during pregnancy: a systematic review and meta-analysis. Sleep Med Rev. 2018, 40:43-54.

\section{Received: 07.07.2021 \\ Accepted for publication: 20.10.2021}

\section{Addresses for correspondence:}

Ali Hasanpour Dehkordi

Social Determinants of Health Research Center, School of Allied Medical Sciences,

Shahrekord University of Medical Sciences,

Shahrekord, Iran

email: alihassanpourdehkordi@gmail.com \&

Reza Ghanei Gheshlagh.

Spiritual Health Research Center,

Research Institute for Health Development,

Kurdistan University of Medical Sciences,

Sanandaj, Iran.

email: rezaghanei30@yahoo.com

Tel: +989144050284 